\title{
Lip and Oral Cavity
}

National Cancer Institute

\section{Source}

National Cancer Institute. Lip and Oral Cavity. NCI Thesaurus. Code C54224.

The lips are the structures that surround the mouth, which is the oral aperture that opens into the oral cavity. The oral cavity is the space bounded superiorly by the hard and soft palates, inferiorly by the tongue and laterally by the cheeks. 